\title{
CONTRIBUTING FACTORS AND KNOWLEDGE OF POLYCYSTIC OVARIAN SYNDROME (PCOS) AMONG PRE-CLINICAL FEMALE STUDENTS IN FMHS, UNIMAS
}

\author{
Arnold Thomas \\ Faculty of Medicine and Health Sciences, Universiti Malaysia Sarawak, Kota Samarahan, \\ Sarawak, Malaysia \\ Liew Yee Xin \\ Faculty of Medicine and Health Sciences, Universiti Malaysia Sarawak, Kota Samarahan, \\ Sarawak, Malaysia
}

\section{Mazwanee Arena Mohamad Raba'ai}

Faculty of Medicine and Health Sciences, Universiti Malaysia Sarawak, Kota Samarahan, Sarawak, Malaysia

\section{Nur Ain Rahmatullah}

Faculty of Medicine and Health Sciences, Universiti Malaysia Sarawak, Kota Samarahan, Sarawak, Malaysia

\section{Saiful Bahri Talip}

Faculty of Medicine and Health Sciences, Universiti Malaysia Sarawak, Kota Samarahan, Sarawak, Malaysia

\section{Siti Maryam Ahmad Kendong}

Faculty of Medicine and Health Sciences, Universiti Malaysia Sarawak, Kota Samarahan, Sarawak, Malaysia

*Corresponding author

E-mail: aksmaryam@unimas.my 


\begin{abstract}
Polycystic Ovary Syndrome (PCOS) is an endocrine disorder of uncertain aetiology that affects women of reproductive age, characterized by features of anovulation, irregular menstrual cycle, hirsutism and acne. Although it is the commonest cause for infertility, most women remain unaware until diagnosed. This was a cross-sectional study using quantitative research approach to collect information from preclinical female students in Faculty of Health and Medicine (FMHS), UNIMAS regarding contributing factors such as Body Mass Index (BMI), menstrual cycle, lifestyle patterns and knowledge on PCOS. A total of 201 respondents participated in which 122 of them medical students and 79 were nursing students. One of the main findings of this study was that most of the students were found to be classified under ideal BMI, 12.4\% were overweight and $14.9 \%$ were underweight. Statistical analysis indicated that there was no difference in the nutritional status of the medical and nursing students. The students were found to be significantly associated with pre-menstrual symptoms (PMS) and their menstrual cycle patterns were found to be significantly irregular due to stress $(p<0.05)$. Majority of the medical and nursing students enjoyed going to the gym during their leisure time $(p<0.05)$. Moreover, both medical and nursing students practiced sedentary activities during leisure time as their mean scores fell below 1.50. The medical students were significantly $(p=0.002)$ more knowledgeable (Mean $=0.38 ; S D=0.20$ ) compared to nursing students (Mean=0.28; $S D=0.21$ ). Nevertheless, both groups were considered having poor knowledge on PCOS as their mean score fell below 0.5 .
\end{abstract}

Keywords: PCOS, menstrual cycle, obesity, lifestyle, knowledge

\title{
INTRODUCTION
}

Polycystic ovary syndrome (PCOS) is a health problem that can affect a woman's menstrual cycle, fertility and hormonal balance. Its pathophysiology, most likely a combination of genetic disposition and environmental factors and the cause of this problem is not well understood (Legro \& Strauss, 2002). PCOS is the commonest health problem associated with endocrine disturbance in women during their reproductive years and it is also the commonest cause of an ovulatory infertility and hirsutism worldwide (Balen, 1999).

The pathogenesis of PCOS is poorly understood, but the primary defect may be involving insulin resistance which leads to hyperinsulinemia. In the ovary, the important feature of this syndrome is functional hyperandrogenism. Circulating concentrations of insulin and luteinising hormone (LH) are generally raised. The theca cells which envelop the follicle and produce androgens for conversion in the ovary to oestrogen are over-responsive to this stimulation. They increase in size and overproduce androgens. The rise in LH levels is thought to be caused by the relatively high and unchanging concentration of oestrogens that may alter the control of this hormone by the hypothalamic-pituitary axis (HPA). This combination of raised levels of androgens, oestrogen, insulin and LH explains the classic PCOS presentation of hirsutism, anovulation or dysfunctional bleeding, and dysfunction of glucose metabolism (Norman et al., 2004).

Women with PCOS usually have missed or irregular periods (Schmid et al., 2004), hirsutism, obesity, infertility, anovulation and acne, which can lead to mood disturbances that include the symptoms of depression, marital and social maladjustment as well as impaired sexual functioning (Hahn et al., 2005).

BMI describes relative weight for height. It is the best method of categorizing whether or not one is underweight or overweight. It is not gender specific and is significantly correlated with the total body fat content. BMI is calculated by dividing weight in kilograms by height in meters squared. The link between PCOS and obesity is complicated. Signs and symptoms of PCOS begin for some females 
soon after they start having periods. It is clear that women affected by obesity have a greater risk for PCOS and vice versa. Obesity is very common clinical feature in women affected by PCOS. In fact, approximately $50 \%$ of PCOS women are overweight or obese and the history of the weight gain frequently precedes the history of oligomenorrhea and hyperandrogenism. This suggested a pathogenic role of obesity in the subsequent development of syndrome (Sheik, 2015).

Women affected with PCOS are associated with impaired glucose tolerance hyperinsulinemia and thus they are at higher risk for developing type 2 diabetes mellitus (Bennal \& Kerure, 2013). Study conducted by Frank et al. (2001) had found that in the large cohort of middle-aged women, a combination of several lifestyle factors, including maintaining a body-mass index of 25 or lower, eating a diet high in cereal fibre, exercising regularly, abstaining from smoking, and consuming alcohol moderately, was associated with an incidence of type 2 diabetes that was approximately 90 per cent lower than that found among women without these factors. Nowadays, most medical students have little knowledge on the contributing factors of PCOS. Moreover, most of them do not have any idea what PCOS is and have never heard about it. These are worrying as they might be having PCOS without realizing it. It is estimated that up to $20 \%$ of women (Hoda Abdel Azim Mohamed, 2016) may be affected by PCOS, but not all of them display symptoms, seek medical assistance or are accurately diagnosed. Menstrual disturbances are the commonest presenting complaint in the adolescent age group and unhygienic practices during menstruation can lead to untoward consequences like pelvic inflammatory diseases and even infertility (Lakkawar et al., 2014). In a study done by Sharma et al. (2013), it was found that among 209 girls, irregular menses were reported by $43 \%$ of medical students and 51 out of 75 were having PCOS. Medical students are at high risk for developing menstrual irregularities due to stressful lifestyle, irregular food intake and exercise habits. Menstrual irregularity over prolonged periods of time can cause anovulation, endometrial hyperplasia and infertility as well as deterioration in the quality of life (El-Gilany, 2005). Therefore, we focused on the health and lifestyle of female students in Faculty of Medicine and Health Sciences.

\section{METHODS}

\section{Research design}

This was a cross-sectional study using a quantitative research approach to collect data from pre-clinical female students from Faculty of Health and Medicine (FMHS), UNIMAS regarding their BMI, menstrual cycle, lifestyle patterns and knowledge on PCOS. The students were divided into two groups of students which were preclinical students from medical and nursing program.

\section{Study setting}

The target participants for this study were undergraduate students from FMHS, UNIMAS which consist of year 1 and year 2 medical and nursing students. The research was conducted at the main campus of UNIMAS and the respondents were given privilege to fill in the questionnaires at their own preferred venue within the allocated time duration.

\section{Study sample}

The target participants for this study were year 1 and year 2 female medical and nursing students. The number of year 1 and year 2 female medical students who participated were 62 and 60 respectively. Meanwhile, the year 1 and year 2 female nursing students who participated were 40 and 39 respectively. Convenient sampling was done and a total number of 201 participants were obtained. 


\section{Research tool}

A questionnaire with 4 main sections was developed which includes socio-demographic characteristics of respondents, menstrual cycle pattern, lifestyle pattern and knowledge on PCOS. The first section were for the participants to fill in on their personal details such as age, course of study (medicine or nursing program), race, height, weight and their recent medical check-up.

Meanwhile, section B of the questionnaire was for information regarding their menstrual cycle pattern. The respondents were required to tick 'YES', 'NO' or 'UNSURE' in the column provided next to the questions.

Section C encompassed information related to their lifestyle pattern which further divides into two parts specifically; activities during their leisure time and their daily consume. In the first part (part A), the respondents were required to tick 'YES', 'NO' or 'UNSURE' in the column provided next to the questions related to activities during leisure time. As for the second part (part B), the respondents needed to select a few answer choices which best represent their eating habit.

In the last section, which is Section D, respondents were tested on their knowledge on PCOS by selecting either 'YES', 'NO' or 'UNSURE' to the questions related to PCOS. The questions in this section include PCOS manifestation, its causes, and its effects.

Before conducting the real survey, the questionnaire was pre-tested. Several changes were done on the questionnaire following the pilot study in regards to the feedback given after the pre-test. The entire questionnaire was written in English.

\section{Data collection}

Consent forms were given to the respondents prior to data collection. The respondents' participation was entirely voluntarily and they understood that they may withdraw from the study at any time. The data obtained is confidential and shall not be shared to outside party. Respondents' identities were kept anonymous.

The targeted respondents were given the questionnaires and asked to complete the questionnaires within appropriate time duration. The questionnaires were then collected immediately after the respondents had finished answering. The duration of the whole data collection from the participants took about two weeks to complete and a total of 201 respondents agreed to participate and had successfully completed the questionnaires. There were no questionnaires lost during this study as they were immediately collected.

\section{Analysis}

The data was checked for missing data prior to being analysed. The quantitative data that were obtained from pre-clinical medical and nursing students were analysed using SPSS software version 22. Descriptive analysis and cross tabulation was used for data tabulation. All data were first expressed in frequency and percentages. However, menstrual cycle pattern, activities done during leisure time and knowledge on PCOS were expressed in mean and standard deviation and tested for independent t-test. The independent-t-test was used to determine the mean difference of these parameters between the two groups. The alpha value was set at 0.05 . Mean score for both medical and nursing students were calculated to investigate the inclination towards normal or abnormal menstrual cycle, doing sedentary or non-sedentary activities during leisure time and having good or poor knowledge on PCOS. Graphical data presentation was used when necessary. 


\section{RESULT}

\section{Body Mass Index (BMI)}

There was no significant association between the body weight status with the grouping variables ( $\mathrm{p}=$ 0.708). Most of the students were having normal BMI (18.5 until 24.9); 72.1\% of medical students and $73.4 \%$ of nursing students. $16.4 \%$ medical students and $12.7 \%$ nursing students were underweight $(\mathrm{BMI}<18.5)$. Only $11.5 \%$ medical students and $13.9 \%$ nursing students were overweight $(\mathrm{BMI}>25.0)$.

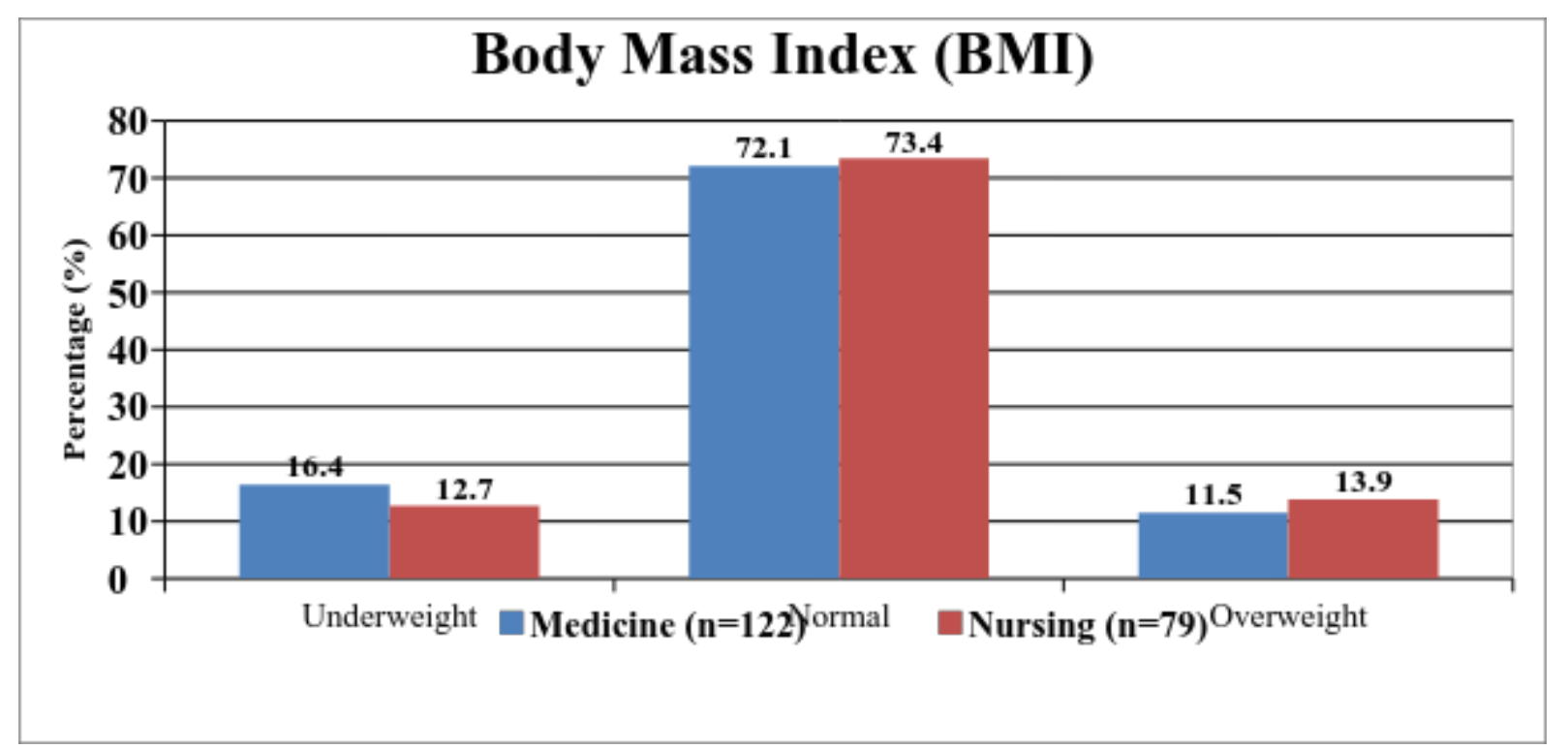

Figure 1: Bar chart shows Body Mass Index (BMI) of the respondents.

\section{Menstrual cycle pattern}

A Chi-square test was done to evaluate pre-menstrual syndrome and menstrual pattern, and their association with the respondents. Majority of both medical and nursing students experienced premenstrual mood swings at significantly $73 \%$ and $82.3 \%$ respectively $(\mathrm{p}<0.05)$.

Table 1:

Percentage distribution of pre-menstrual syndrome experienced by respondents.

\begin{tabular}{|c|c|c|c|c|c|c|c|c|}
\hline \multirow[t]{3}{*}{ No. } & \multirow[t]{3}{*}{ Pre-menstrual syndrome } & \multicolumn{3}{|c|}{ Medical $(n=122)$} & \multicolumn{3}{|c|}{ Nursing $(n=79)$} & \multirow{3}{*}{$\begin{array}{l}p \text {-value } \\
\text { of Chi } \\
\text { square }\end{array}$} \\
\hline & & \multicolumn{6}{|c|}{ Percentage (\%) } & \\
\hline & & Yes & No & Unsure & Yes & No & Unsure & \\
\hline 1. & $\begin{array}{l}\text { Experience premenstrual } \\
\text { mood swings (frustration, } \\
\text { anger, irritability) }\end{array}$ & 73.0 & 12.3 & 14.8 & 82.3 & 13.9 & 3.8 & 0.046 \\
\hline 2. & $\begin{array}{l}\text { Experience food craving } \\
\text { before period }\end{array}$ & 70.5 & 23.8 & 5.7 & 78.5 & 11.4 & 10.1 & 0.063 \\
\hline 3. & $\begin{array}{l}\text { Experience breast tenderness } \\
\text { or swelling before period }\end{array}$ & 42.6 & 35.2 & 22.1 & 43.0 & 32.9 & 24.1 & 0.925 \\
\hline 4. & $\begin{array}{l}\text { Acne problem before } \\
\text { menstrual cycle starts }\end{array}$ & 66.4 & 23.8 & 9.8 & 68.4 & 17.7 & 13.9 & 0.461 \\
\hline
\end{tabular}


Based on the data analysis, we found that stress significantly results in irregular menstrual cycle pattern among both medical and nursing students $(\mathrm{p}<0.05)$.

Table 2

The menstrual cycle pattern among medical and nursing students.

\begin{tabular}{|c|c|c|c|c|c|c|c|c|}
\hline \multirow[t]{3}{*}{ No. } & \multirow[t]{3}{*}{ Menstrual pattern } & \multicolumn{3}{|c|}{ Medical $(n=122)$} & \multicolumn{3}{|c|}{ Nursing $(n=79)$} & \multirow{3}{*}{$\begin{array}{l}p \text {-value } \\
\text { of Chi } \\
\text { square }\end{array}$} \\
\hline & & \multicolumn{6}{|c|}{ Percentage (\%) } & \\
\hline & & Yes & No & Unsure & Yes & No & Unsure & \\
\hline 1. & $\begin{array}{l}\text { Menstrual cycle shorter than } 26 \\
\text { days (-) }\end{array}$ & 28.7 & 49.2 & 22.1 & 39.2 & 39.2 & 21.5 & 0.262 \\
\hline 2. & $\begin{array}{l}\text { Menstrual cycle longer than } 31 \\
\text { days (-) }\end{array}$ & 18.9 & 61.5 & 19.7 & 17.7 & 64.6 & 17.7 & 0.904 \\
\hline 3. & $\begin{array}{l}\text { Miss periods or have long breaks } \\
\text { between periods (-) }\end{array}$ & 39.3 & 54.9 & 5.7 & 38.0 & 55.7 & 6.3 & 0.972 \\
\hline 4. & $\begin{array}{l}\text { Experience irregular bleeding or } \\
\text { have short breaks between periods } \\
(-)\end{array}$ & 34.4 & 58.2 & 7.4 & 20.3 & 70.9 & 8.9 & 0.096 \\
\hline 5. & $\begin{array}{l}\text { Stress makes menstrual cycle } \\
\text { length more irregular (-) }\end{array}$ & 52.5 & 21.3 & 26.2 & 32.9 & 31.6 & 35.4 & 0.024 \\
\hline 6. & $\begin{array}{l}\text { Experience heavy bleeding after 3- } \\
4 \text { days (-) }\end{array}$ & 15.6 & 76.2 & 8.2 & 22.8 & 69.6 & 7.6 & 0.436 \\
\hline 7. & $\begin{array}{l}\text { Experience light bleeding for the } \\
\text { whole period time (-) }\end{array}$ & 25.4 & 65.6 & 9.0 & 22.8 & 65.8 & 11.4 & 0.815 \\
\hline 8. & $\begin{array}{l}\text { Experience strong pelvic cramping } \\
\text { with sharp pain or nausea during } \\
\text { period (-) }\end{array}$ & 54.1 & 35.2 & 10.7 & 43.0 & 49.4 & 7.6 & 0.135 \\
\hline 9. & $\begin{array}{l}\text { Experience period pain that when } \\
\text { soothed by warmth and pressure } \\
\text { (eg. Hug hot water bottle), the pain } \\
\text { relieved }(+)\end{array}$ & 63.9 & 23.8 & 12.3 & 69.6 & 22.8 & 7.6 & 0.530 \\
\hline 10. & $\begin{array}{l}\text { Experience headache during period } \\
(-)\end{array}$ & 38.5 & 51.6 & 9.8 & 38 & 44.3 & 17.7 & 0.242 \\
\hline 11. & $\begin{array}{l}\text { Feeling uncomfortable during } \\
\text { period (-) }\end{array}$ & 85.2 & 10.7 & 4.1 & 86.1 & 10.1 & 3.8 & 0.986 \\
\hline 12. & $\begin{array}{l}\text { Entire symptoms improve if not } \\
\text { under stress }(+)\end{array}$ & 28.7 & 25.4 & 45.9 & 22.8 & 26.6 & 50.6 & 0.643 \\
\hline 13. & $\begin{array}{l}\text { Entire symptom improve if just } \\
\text { lying down }(+)\end{array}$ & 63.1 & 19.7 & 17.2 & 54.4 & 27.8 & 17.7 & 0.365 \\
\hline 14. & $\begin{array}{l}\text { Feeling exhausted, pale and } \\
\text { fatigues after period }(-)\end{array}$ & 36.9 & 49.2 & 13.9 & 32.9 & 50.6 & 16.5 & 0.803 \\
\hline
\end{tabular}

An independent sample t-test was done to find the mean difference of score on menstrual pattern among medical and nursing students. The mean score was higher among the nursing students (Mean $=0.50$; $\mathrm{SD}=0.17$ ) compared to medical students (Mean=0.49; $\mathrm{SD}=0.18$ ). However, it was not statistically significant $(p>0.05)$.

\section{Lifestyle Pattern}

To assess the lifestyle pattern of female medical and nursing students, a total of 17 questions were asked 
regarding activities done during leisure time, 3 questions on lifestyle practices and 13 questions on diet of respondents. Amongst the different kind of activities, both medical and nursing students prefer going to the gym during their leisure time $(\mathrm{p}<0.05)$.

Table 3

Activities done during the leisure time of the respondents.

\begin{tabular}{|c|c|c|c|c|c|c|c|c|c|c|}
\hline \multirow[t]{3}{*}{ No. } & \multirow{3}{*}{$\begin{array}{l}\text { Activities done during } \\
\text { leisure time }\end{array}$} & \multicolumn{4}{|c|}{ Medical $(n=122)$} & \multicolumn{4}{|c|}{ Nursing $(n=79)$} & \multirow{3}{*}{$\begin{array}{l}p \text {-value of } \\
\text { Chi Square }\end{array}$} \\
\hline & & \multicolumn{8}{|c|}{ Percentage (\%) } & \\
\hline & & A & B & $\mathrm{C}$ & $\mathrm{D}$ & $\mathrm{A}$ & B & $\mathrm{C}$ & $\mathrm{D}$ & \\
\hline 1. & Going to gym (+) & 1.6 & 0.8 & 29.5 & 68.0 & 0.0 & 0.0 & 13.9 & 86.1 & 0.029 \\
\hline 2. & Jogging $(+)$ & 2.5 & 13.1 & 75.4 & 9.0 & 0.0 & 5.1 & 83.5 & 11.4 & 0.125 \\
\hline 3. & Playing Sports $(+)$ & 0.8 & 16.4 & 73 & 9.8 & 1.3 & 8.9 & 69.6 & 20.3 & 0.115 \\
\hline 4. & $\begin{array}{l}\text { Doing Physical } \\
\text { Activity }(+)\end{array}$ & 3.3 & 32.0 & 59.8 & 4.9 & 3.8 & 17.7 & 73.4 & 5.1 & 0.166 \\
\hline 5. & Dancing $(+)$ & 2.5 & 11.5 & 54.1 & 32.0 & 2.5 & 8.9 & 44.3 & 44.3 & 0.360 \\
\hline 6. & Doing Yoga (+) & 1.6 & 1.6 & 15.6 & 81.1 & 1.3 & 0.0 & 11.4 & 87.3 & 0.540 \\
\hline 7. & Walking $(+)$ & 19.7 & 31.7 & 41.8 & 0.8 & 26.6 & 24.1 & 45.6 & 3.8 & 0.108 \\
\hline 8. & Studying (-) & 27.9 & 50.8 & 21.3 & 0.0 & 31.6 & 45.6 & 21.5 & 1.3 & 0.562 \\
\hline 9. & Sleeping (-) & 32.8 & 53.3 & 13.1 & 0.8 & 44.3 & 39.2 & 15.2 & 1.3 & 0.269 \\
\hline 10. & Watching Movie (-) & 13.9 & 43.4 & 41.0 & 1.6 & 20.3 & 30.4 & 48.1 & 1.3 & 0.272 \\
\hline 11. & Doing Housework $(+)$ & 19.7 & 43.4 & 36.1 & 0.8 & 20.3 & 44.3 & 34.2 & 1.3 & 0.984 \\
\hline 12. & Socializing (-) & 23.0 & 50.0 & 25.4 & 1.6 & 20.3 & 46.8 & 30.4 & 2.5 & 0.830 \\
\hline 13. & Shopping $(+)$ & 15.6 & 33.6 & 20.8 & 0.0 & 15.2 & 29.1 & 54.4 & 1.3 & 0.578 \\
\hline 14. & Social Networking (-) & 26.2 & 49.2 & 23.8 & 0.8 & 20.3 & 49.4 & 29.1 & 1.3 & 0.719 \\
\hline 15. & Eating Fast Food $(-)$ & 8.2 & 22.1 & 69.7 & 0.0 & 10.1 & 16.5 & 69.6 & 3.8 & 0.132 \\
\hline 16. & Reading Book (-) & 14.8 & 49.2 & 35.2 & 0.8 & 19.0 & 38.0 & 43.0 & 0.0 & 0.351 \\
\hline 17. & $\begin{array}{l}\text { Browsing the internet } \\
(-)\end{array}$ & 18.0 & 39.3 & 32.8 & 9.8 & 19.0 & 34.2 & 39.2 & 7.6 & 0.753 \\
\hline & & Every & ne, $B=$ & Iost of & e tim & $C=$ Son & times, & $=$ Neve & & \\
\hline
\end{tabular}

It was found that all of the respondents never smoke. However, a small percentage of medical (7.4\%) and nursing (8.9\%) students drank alcohol sometimes.

To investigate the dietary pattern of the respondents, 13 multiple response questions were included in the questionnaire. $94.5 \%$ of the respondents consumed rice every day, $84.1 \%$ chicken, $83.6 \%$ fish, $39.8 \%$ vegetables and egg. Only $28.4 \%$ of the respondents consumed noodle, $14.4 \%$ fruits and $5 \%$ cakes. 


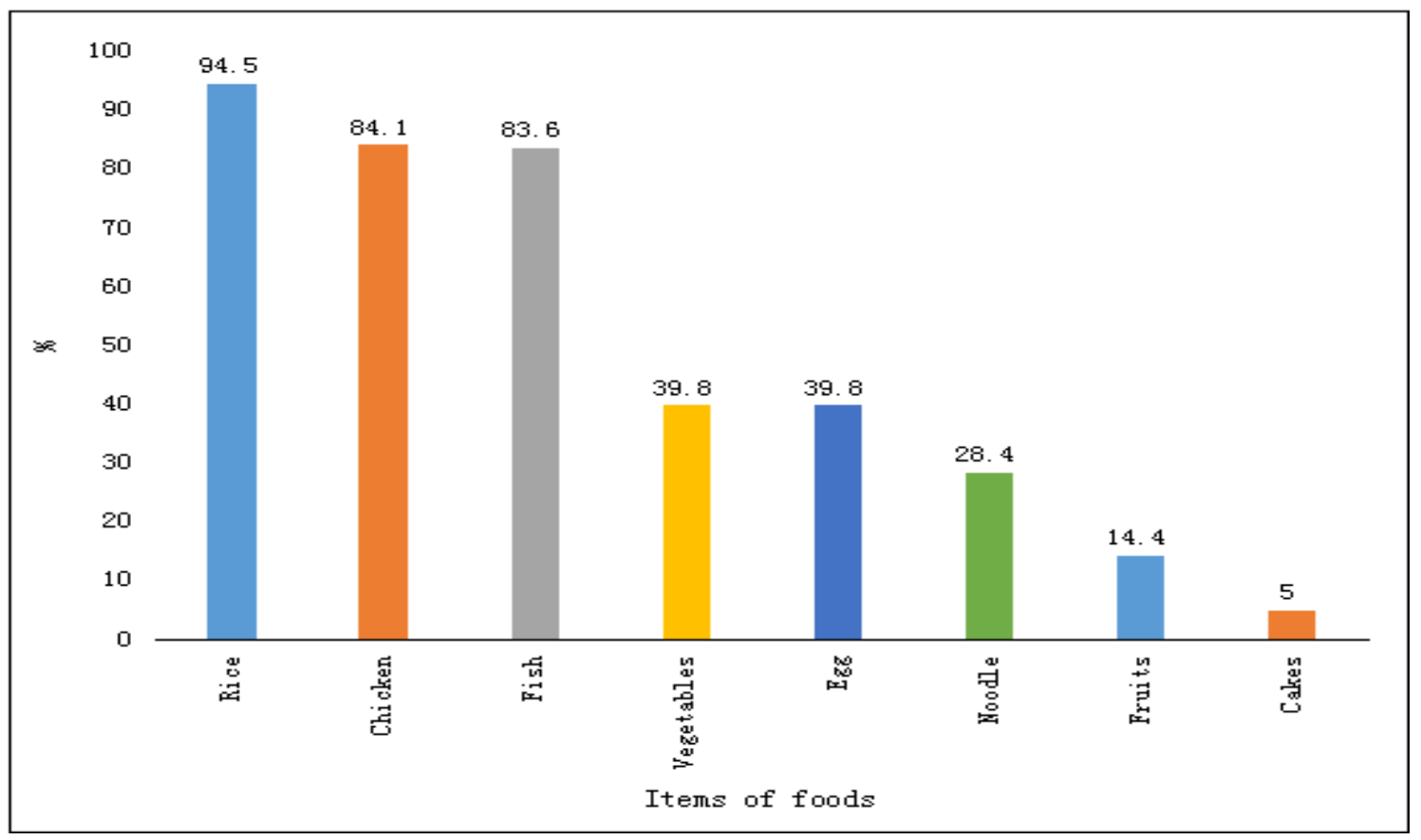

Figure 5. Bar chart showing student's food intake

Majority of students had meals twice a day (50.2\%), while slightly less prefer to have thrice a day $(38.3 \%)$. Most students $(93.5 \%)$ take just one plate for every meal, while only a few $(6.5 \%)$ take two plates per meal.

$81.6 \%$ of the students chose to have the heaviest meal during their lunch time. Most students take fruits $(70.6 \%)$ sometimes as their dessert or confectionary $(80.6 \%)$. Majority of the students take soft drinks sometimes $(84.1 \%)$.

Table 5

Eating pattern of the respondents

\begin{tabular}{lcc}
\hline Variables & $\mathbf{N}$ & $\mathbf{\%}$ \\
\hline Meal per day & 17 & 8.5 \\
Once & 101 & 50.2 \\
Twice & 77 & 38.3 \\
Thrice & 9 & 4.5 \\
More than thrice & 188 & 93.5 \\
Plate per meal & 13 & 6.5 \\
One plate & & 12.9 \\
Two plates & 26 & 8.0 \\
Heaviest mealtime consumed & 16 & 81.6 \\
During breakfast & 164 & 1.0 \\
During brunch (between breakfast and lunch) & 2 & 22.4 \\
During lunch & 45 & 4.5 \\
During teatime & & 20.4 \\
During dinner & 9 & 63.2 \\
Read and use food labels & 41 & 12.4 \\
Every time & 127 & 7.5 \\
Most of the time & 25 & \\
Sometimes & & \\
Never & 15 & \\
Frequency of choosing food with less sugar & & \\
Every time & & \\
\hline
\end{tabular}




\begin{tabular}{lcc}
\hline Most of the time & 67 & 33.3 \\
Sometimes & 110 & 54.7 \\
Never & 9 & 4.5 \\
Dietary Restriction & 17 & 8.5 \\
Salt & 35 & 17.4 \\
Fat & 1 & 0.5 \\
Fluid & 158 & 78.6 \\
None & 4 & 2.0 \\
Frequency consume dessert or confectionery & 33 & 16.4 \\
Every time & 162 & 80.6 \\
Most of the time & 2 & 1.0 \\
Sometimes & & \\
Never & 142 & 70.6 \\
Type of dessert or confectionery & 26 & 12.9 \\
Fruit & 51 & 25.4 \\
Candy & 54 & 26.9 \\
Cakes & 58 & 28.9 \\
Cookies & & \\
Ice-cream & 16 & 8.0 \\
Frequency of drinking soft drink & 169 & 84.1 \\
Most of the time & 17 & 8.5 \\
Sometimes & & \\
Never & & 23.4 \\
Teaspoon of sugar in a cup of tea & 47 & 28.9 \\
Half teaspoon & 58 & 22.4 \\
Full one teaspoon & 45 & 12.9 \\
One and a half teaspoon & 26 & 8.5 \\
Full two teaspoon & 17 & 5.0 \\
None & & 10.9 \\
Frequency of adding sugar in cooking & 10 & 56.7 \\
Every time & 22 & 27.4 \\
Most of the time & 114 & \\
Sometimes & 55 & \\
Never & & \\
\hline & & \\
& &
\end{tabular}

\section{Knowledge on PCOS}

To assess the knowledge on PCOS of female medical and nursing students, a total of 18 questions were asked. Out of 18 questions, 2 were negative statements. The respondents having correct answers were scored as ' 1 ' and incorrect or unsure answers as ' 0 '. Independent t-test was done to calculate mean difference of knowledge on PCOS between medical and nursing students. The mean score was higher among the medical students (Mean=0.38; $\mathrm{SD}=0.20$ ) compared to nursing students (Mean=0.28; $\mathrm{SD}=0.21)$. The mean difference was statistically significant $(p<0.05)$ since $p$-value was 0.002 .

Table 6

Knowledge on PCOS between medical and nursing students.

\begin{tabular}{|c|c|c|c|c|c|c|c|c|}
\hline \multirow[t]{3}{*}{ No. } & \multirow[t]{3}{*}{ Knowledge on PCOS } & \multicolumn{3}{|c|}{ Medical $(n=122)$} & \multicolumn{3}{|c|}{ Nursing $(n=79)$} & \multirow{3}{*}{$\begin{array}{l}p \text {-value of } \\
\text { Chi square }\end{array}$} \\
\hline & & \multicolumn{6}{|c|}{ Percentage (\%) } & \\
\hline & & Yes & No & Unsure & Yes & No & Unsure & \\
\hline 1. & Heard of PCOS $(+)$ & 48.4 & 41.0 & 10.7 & 24.1 & 64.6 & 11.4 & 0.002 \\
\hline 2. & Know what is $\operatorname{PCOS}(+)$ & 25.4 & 51.6 & 23.0 & 8.9 & 68.4 & 22.8 & 0.010 \\
\hline 3. & PCOS is life threatening & 53.3 & 16.4 & 30.3 & 40.5 & 13.9 & 45.6 & 0.087 \\
\hline
\end{tabular}




\begin{tabular}{|c|c|c|c|c|c|c|c|c|}
\hline \multirow[b]{2}{*}{4.} & \multicolumn{8}{|l|}{$(+)$} \\
\hline & $\begin{array}{l}\text { PCOS is due to } \\
\text { pathogen infection (-) }\end{array}$ & 25.4 & 13.1 & 61.5 & 29.1 & 15.2 & 55.7 & 0.718 \\
\hline 5. & PCOS is a tumour (-) & 36.9 & 14.8 & 48.4 & 31.6 & 8.9 & 59.5 & 0.241 \\
\hline 6. & $\begin{array}{l}\text { PCOS is due to } \\
\text { hormone imbalance }(+)\end{array}$ & 59.8 & 3.3 & 36.9 & 46.8 & 1.3 & 51.9 & 0.091 \\
\hline 7. & $\begin{array}{l}\text { PCOS is an inherited } \\
\text { disease }(+)\end{array}$ & 28.7 & 13.9 & 57.4 & 16.5 & 24.1 & 59.5 & 0.056 \\
\hline 8. & $\begin{array}{l}\text { PCOS cause difficulty } \\
\text { in conceiving }(+)\end{array}$ & 53.3 & 1.6 & 45.1 & 35.4 & 0.0 & 64.6 & 0.018 \\
\hline 9. & $\begin{array}{l}\text { Female can produce } \\
\text { testosterone }(+)\end{array}$ & 68.0 & 5.7 & 26.2 & 45.6 & 7.6 & 46.8 & 0.006 \\
\hline 10. & $\begin{array}{l}\text { PCOS affects female's } \\
\text { menstrual cycle }(+)\end{array}$ & 79.5 & 1.6 & 18.9 & 68.4 & 2.5 & 29.1 & 0.203 \\
\hline 11. & $\begin{array}{l}\text { Overweight female } \\
\text { (BMI>25.0) may have } \\
\text { PCOS }(+)\end{array}$ & 37.7 & 3.3 & 59.0 & 27.8 & 6.3 & 65.8 & 0.255 \\
\hline 12. & $\begin{array}{l}\text { Diabetes patient may } \\
\text { have PCOS }(+)\end{array}$ & 27.9 & 4.9 & 67.2 & 24.1 & 2.5 & 73.4 & 0.544 \\
\hline 13. & $\begin{array}{l}\text { PCOS can be prevented } \\
\text { by exercise regularly } \\
(+)\end{array}$ & 33.6 & 2.5 & 63.9 & 34.2 & 3.8 & 62.0 & 0.852 \\
\hline 14. & $\begin{array}{l}\text { PCOS can be prevented } \\
\text { by aware about what } \\
\text { one consumes }(+)\end{array}$ & 65.6 & 0.0 & 34.4 & 49.4 & 1.3 & 49.4 & 0.042 \\
\hline 15. & $\begin{array}{l}\text { PCOS can be treated by } \\
\text { consuming combination } \\
\text { of birth control pills that } \\
\text { regulate menses }(+)\end{array}$ & 8.2 & 13.9 & 77.9 & 13.9 & 17.7 & 68.4 & 0.281 \\
\hline 16. & $\begin{array}{l}\text { PCOS can be treated by } \\
\text { consuming metformin } \\
(+)\end{array}$ & 5.7 & 9.8 & 84.4 & 3.0 & 6.0 & 88.6 & 0.694 \\
\hline 17. & $\begin{array}{l}\text { PCOS can be treated by } \\
\text { removing part of ovary } \\
\text { to regulate menses and } \\
\text { start normal ovulation } \\
(+)\end{array}$ & 22.1 & 4.1 & 73.8 & 20.3 & 3.8 & 75.9 & 0.942 \\
\hline 18. & $\begin{array}{l}\text { Ovarian wedge } \\
\text { resection can damage } \\
\text { ovary }(+)\end{array}$ & 30.3 & 7.4 & 62.3 & 26.6 & 6.3 & 67.1 & 0.786 \\
\hline
\end{tabular}

\section{DISCUSSION}

Most of the respondents had a normal BMI (72.1\%) which was in a range of 18.5-24.9. This finding corresponded with a study done by Yahia, Achkar, Abdallah and Rizk (2008) that showed majority of the female students $(76.8 \%$ ) were having a normal weight. Predominantly worrying is the rising tide of childhood obesity that has resulted in an increase in the prevalence and severity of symptoms of PCOS in adolescent girls (Franks, 2008). Fortunately, in this study, there were only a few overweight students.

The students were found to be highly associated with pre-menstrual symptoms. This may lead to lack of commitment in daily activities, lecture absenteeism and socially inactive. Stress was also found to be responsible for the irregularities of the menstrual cycle pattern. Students of the medical program are highly exposed to stressful situations throughout their study program, which is thought to be the stimulus for the menstrual irregularities. A similar study on 107 female medical students of Shyam Shah Medical College found that dysmenorrhea and pre-menstrual symptoms were common 
(73.83\%) and they were found to skip classes, reduce social and other daily activities (Singh et al., 2008). As for menstrual cycle pattern, mean score of less than 0.5 shows inclination to irregular menstrual cycle and mean score of 0.5 and above indicates regular menstrual cycle. Based on the mean score, it was found that the nursing students in this study had regular menstrual cycle while medical students had irregular menstrual cycle. Nevertheless, it was insignificant. Having irregular menstrual cycle was a concerning fact considering that there was relationship between irregular menstrual cycles to development of insulin resistance and type 2 diabetes mellitus independent to attribution of being overweight (Solomon, 2001). This later on, is believed to initiate the development of PCOS.

There was no huge difference between both groups in term of practicing healthy lifestyle including physical activity, dietary, stress, alcohol and smoking. Medical and nursing students had the same medical background so that the lifestyle pattern were practically equivalent. Through our findings, regarding activities done during leisure time, the mean score was higher among the medical students (Mean=1.15) compared to nursing students (Mean=1.10) however the cut-off point was 1.5 whereby mean score of 1.5 and above means more non-sedentary activities were done. Both mean scores of medical and nursing students showed both inclined towards sedentary activities as both had mean score lower than 1.5. This could be the result of lack of time, packed-day schedule and extreme tiredness among medical and nursing students which was supported by a study done by Gomez-Lopez, Gallegos and Extremera (2010) in which they found that lack of time, stress and tiredness prompted by the work or study overload could be the reason of low practices of physical activities. To relate lifestyle and PCOS, Lamb et al. (2011) stated in their study that both metabolic and reproductive manifestations of PCOS can be improved by lifestyle modifications. Their outcome showed that increased odds of obesity, waist circumferences, impaired fasting glucose and mild depression were associated with physical activity absentee which in a long run, could initiate PCOS.

Regarding the knowledge on PCOS, almost half of medical students (48.4\%) have heard of PCOS but majority of nursing students (64.6\%) have never heard of PCOS before. According to Hoda Abdel Azim Mohamed (2016), before utilization of educational sessions, most of the students (84.4\%) from Faculty of Nursing at Minia University had poor knowledge regarding PCOS. After the educational sessions there was enhancement of knowledge score on PCOS. The findings of the present study showed that vast majority of studied nurses had never attended any formal training program about PCOS and the majority of them did not have any information regarding PCOS (Amasha \& Heeba, 2014).

Urgent solutions to address the issue on lack of knowledge on PCOS among nursing students were necessary as nurses played a pivotal role in educating and empowering women with PCOS (Amasha \& Heeba, 2014). Amasha and Heeba (2014) had concluded that implementation of an education program was efficient in enhancing the level of knowledge of maternity nurses regarding PCOS. Therefore, nurses need to have a broad knowledge on PCOS. As compared to nursing students, medical students in UNIMAS had better understanding about PCOS but still found to be below the mean average $($ Mean $<0.50)$ which indicated they had poor knowledge on PCOS. Thus, various education program is needed to enhance knowledge on PCOS in both medical and nursing students of UNIMAS to improve the medical services in the future.

Future studies should include female students of other faculties, with wider age range. This will give a holistic view of the menstrual cycle pattern and its relation to PCOS.

\section{CONCLUSION}

In general, it was discovered that $72.1 \%$ of respondents' nutritional status were classified under ideal BMI. There were no significant differences between the medical and nursing students' nutritional status. As for the menstrual cycle pattern, majority of the students were found to be significantly associated with pre-menstrual symptoms. Stress was found to be the trigger to menstrual irregularities among the students. As for lifestyle pattern, both medical and nursing students were significantly found to enjoy going to the gym more than others. Both groups were noted to have poor knowledge on PCOS; however, the level of knowledge of the medical students is significantly higher compared to the nursing students. 


\section{LIST OF ABBREVIATIONS}

1. PCOS = Polycystic ovarian syndrome

2. $\mathrm{FMHS}=$ Faculty of Medicine and Health Science

3. UNIMAS = Universiti Malaysia Sarawak

4. $\mathrm{BMI}=$ Body Mass Index

5. HPA = Hypothalamic-Pituitary-Adrenal

6. $\mathrm{LH}=$ Luteinising Hormone

\section{ACKNOWLEDGMENT}

We would like to thank Prof. Dr. Md Mizannur Rahman, Year 1 and Year 2 medical and nursing female student of UNIMAS, our parents, lecturers, and friends for their willingness to spend time to guide us patiently throughout the research.

\section{REFERENCES}

Amasha, H. A., \& Heeba, M. F. (2014). Implementation and Evaluation of Effectiveness of Educating Program for Upgrading Nurses' Knowledge Regarding Polycystic Ovaries Syndrome. Journal of Nursing and Health Science, 3(1), 1-8.

Balen, A. H. (1999). The pathogenesis of polycystic ovary syndrome: the enigma unravels. Lancet, 354(9183), 966-967.

Bennal, A. \& Kerure, S. (2013). Effect of PCOS on Glucose Metabolism. National Journal of Physiology, Pharmacy \& Pharmacology, 3(2), 167-170.

El-Gilany, A.-H., Badawi, K., \& El-Fedawy, S. (2005). Menstrual Hygiene among Adolescent Schoolgirls in Mansoura, Egypt. Reproductive Health Matters, 13(26), 147-152.

Frank, B. H., Joann, E. M., Meir, J. S., Graham, C., Simin, L., Caren, G. S. et al. (2001). Diet, lifestyle, and the risk of Diabetes Type 2 in women. The New England Journal of Medicine, 345(11). 790-797.

Franks, S. (2008). Polycystic ovary syndrome in adolescents. International Journal of Obesity, 32. $1035-1041$.

Gopez-Lopez, M., Gallegos, A. G., \& Extremera, A. B. (2010). Percieved barriers y university students in the practice of physical activity. Journal of Sports Science \& Medicine, 9(3), 374381.

Hahn, S., Janssen, O. E., Tan, S., Pleger, K., Mann, K., Schedlowski, M., et al. (2005). Clinical and psychological correlates of quality-of-life in polycystic ovary syndrome. European Journal of Endocrinology, 153, 853-860.

Hoda Abdel Azim Mohamed (2016). Effect of educational program on the level of knowledge regarding polycystic ovarian syndrome among adolescent girls. Journal of Nursing Education and Practice, 6(10), 80-87.

Lakkawar, N. J., Jayavani R. L., Arthi, N. P., Alaganandam, P. \& Vanajakshi N. (2014). A study of menstrual disorders in medical students and its correlation with biological variables. Scholars Journal of Applied Medical Sciences (SJAMS), 2(6E). 3165-3175.

Lamb, J. D., Johnstone, E. B., Rousseau, J. A., Jones, C. L., Pasch, L. A., Cedars, M. I., \& Huddleston, H. G. (2011). Physical activity in women with polycystic ovary syndrome: prevalence, predictors, and positive health associations. American journal of obstetrics and gynecology, 204(4), 352.

Legro, R. S., \& Strauss, J. F. (2002). Molecular progress in infertility: Polycystic ovary syndrome. Fertil and Steril, 78(3), 569-576.

Norman, R. J., Wu, R., \& Stankiewicz, M. T. (2004). 4: Polycystic ovary syndrome. The Medical Journal of Australia, 180(3), 132-137. 
Polson, D. W., Wadsworth, J., Adams, J., \& Franks, S. (1988). Polycystic ovaries-a common finding in normal women. The Lancet, 331(8590), 870-872.

Schmid, J., Kirchengast, S., Vytiska-Binstorfer, E., \& Huber, J. (2004). Infertility caused by PCOS Health-related quality of life among Austrian and Moslem immigrant women in Austria. Human Reproduction, 19(10), 2251-2257.

Sharma, N., Sharma, P., Sharma, N., Wavare, R.R., Gautam, B. \& Sharma, M. (2013). A cross sectional study of knowledge, attitude and practices of menstrual hygiene among medical students in north India. The Journal of Phytopharmacology, 2(5), 28-37.

Sheik, R. (2015). Awareness of obesity as a risk factor for Polycystic Ovarian Syndrome. Journal of Pharmaceutical Sciences and Research, 7(7). 471-473.

Singh, A., Kiran, D., Singh, H., Nel, B., Singh, P. \& Tiwari, P. (2008). Prevalence and severity of dysmenorrhea: A problem related to menstruation among first and second year medical students. Indian Journal of physiology and pharmacology, 52(4), 389.

Solomon, C. G., Hu, F. B., Dunaif, A., Rich-Edwards, J., Willet, W. C., Hunter, D. J., ... \& Manson, J. E. (2001). Long or highly irregular menstrual cycles as a marker for risk of type 2 diabetes mellitus. Jama, 286(19), 2421-2426.

Yahia, N., Achkar, A., Abdallah, A., \& Rizk, S. (2008). Eating habits and obesity among Lebanese university students. Nutrition Journal, 7(32). 1-6. 